\title{
The Social Constructivist Response to Educational Technology
}

\author{
Dr. Nabil MORCHID
}

Laboratory of Language and Society, Ibn Tofail University, Morocco

\begin{abstract}
The multiple affordances of educational technology are not enough to cause success implementations of technology in education. Theories of knowledge and learning must synchronise with the intent of technology use in education. This paper is set to expose the theoretical and pedagogical mechanisms needed for maximising the reciprocity between education and technology. The constructivist thinking is researched for operational frameworks with the ability to orient technology use in education. The theoretical load of constructivism is optimised to yield distinct learning and teaching practices that carry the epistemological stands of the social constructivist tradition in education. In particular, this paper begins with an analytical perspective as a means for assessing the relationship between education and technology and obtaining credible estimates of the potential of educational technology. Then, the social constructivist thinking is researched for credible itineraries of implementation susceptible to cause valid incorporations of educational technology.
\end{abstract}

Keywords - Constructivism, educational technology, ICT, pedagogy, theory of learning.

\section{INTRODUCTION}

A theory of learning is essential to the wellfunctioning of educational technology because it shapes and orients the process of learning towards distinct goal areas (Doolittle \& Hicks, 2012). The social constructivist tradition in learning is reputed for its ability to convert into distinct learning and teaching strategies. These are empirically valid perspectives of implementation that ensure total reciprocity between the fundamentals of education and the outputs from technology. Social constructivism builds on the impossibility to attain objective knowledge. The knowledge constructs from learning are no exception as they stand dependently of learners' manipulations of their environment. This theoretical tenet has consequences on the optimal learning conditions needed for knowledge construction. Technology is reputed for the impact it has on social activity. If learning is subordinate to social interaction, then the role of technology is to be valued for its contributions to social activity.

Educational technology is an important construct in this study. The relationship between education and technology is essential to a valid conceptualisation of educational technology. This paper is set to expose the theoretical basis of educational technology as a means for substantiating the reciprocity between the social constructivist thinking and educational technology. In particular, this paper is organised to answer two research questions:
- What is the relationship between education and technology?

- Does social constructivism synchronise with the basics of educational technology?

\section{CONCEPTUALISING EDUCATIONAL TECHNOLOGY}

In this paper, the existing knowledge on education and technology is researched for evidence of reciprocity between the two constructs. A substantial body of research attempts to answer questions about the nature of educational technology. The theories on the origin of educational technology capitalise on the agency between education and technology. Although the two constructs combine into a single social phenomenon, they still afford varying degrees of inconformity in terms of theory and practice. This section provides credible explanations about the true character of educational technology from the perspectives of Dewey (1938) and Dusek (2006).

\subsection{Dewey (1938)'s conceptualisation of} educational technology

Dewey (1938)'s conception of education synchronises with the attributes of technology. Education is presented as an ongoing process of orientation with the capacity to evolve and adapt to new contexts. Evolution is the prevailing feature of education; education has the ability to orient and measure up to the advances made in different contexts. Transformation applies to all systems, biological or intellectual, and the same logic applies to education. 
The intercourse between education and technology is a natural response to reality.

Indeed, Dewey's claims on education enable total reciprocity between education and its environment (Lakhana, 2014). Education is a function and a consequence of social life. It is very normal for education to espouse the attributes of technology since these are the outcomes from a real situation. In general terms, the incorporation of technology in education is inevitable. It marks the evolution of an existing system. Disassociating education from technology or vice versa would be like reversing the logic of transformation. Education and technology synchronise into a coherent whole with ample opportunities for authenticity in learning.

Dewey (1938)'s theory about the logic of enquiry offers valid perspective for technology incorporation in education (Bruce \& Levin, 1997, pp. 79-102). The theory centres on the importance of experience in the construction of knowledge. The processes and contexts of education are more consequential than the final outputs from education. For an individual to make the most of a learning activity there must be maximum interactivity with the tools used for acquisition. Knowledge acquisition in any educational process is not an end in itself. It is an instrument for intellectual growth.

Dewey's conception of education has direct implications for technology incorporation in education. Dewey (1938, as cited in Lakhana, 2014, p. 5)'s view of education as "the directed and controlled transformation of indeterminate situation into a determinately unified one" emphasises the role of technology in attaining the objectives from education. Also, Dewey's model of enquiry constitutes the basis for Bruce and Levin (1997)'s framework for integrating technology in education. This framework combines four attributes of educational technology.

The first criterion for a viable use of technology in education capitalises on the role of media as a vehicle for the transmission of information (Bruce and Levin, 1997). Technology is a resource to which educators may turn to foster access to education. Indeed, the existing information communication technologies revolutionise access to education. Learning is no longer confined to schooling facilities and infrastructures. Technology-enhanced media enable new modes of learning. For instance, the continuous advances in computer applications for wordprocessing assist learners in their school writing, the manipulation of smart art and graphics along with multiple modes for the presentation of varied contents (Lakhana, 2014). Most importantly, educational technology does not only foster communication, but it also frees communication of the constraints of time and space. Synchronous communication and asynchronous communication constitute a major contribution to education. They simulate real-life environments for learning. The role of media as a vehicle for education is well suited to the offerings of technology.

The second criterion for the incorporation of technology in education relates to the individual's ability to reach out new meanings of their surroundings information (Bruce and Levin, 1997). This criterion traces back to Dewey's "natural impulses for inquiry" (Lakhana, 2014, p.82). Indeed, learning is a social process and knowledge is the outcome from the individual's interactions with their environment. The use of technology as a means or an instrument of acquisition is due to natural conditions that prioritise distinct modes of learning. The available technologies known to support education are the products of society.

Technology has a goal-oriented approach to education. The third criterion for technology to impact the educational discourse is its ability to convert into quantifiable gains for the individual (Bruce and Levin, 1997). Technology reconciles the abstract loads of knowledge with the possible realisations of education in the physical world. Technology extends the abilities of individuals to impact their environment. In the context of institutionalised education, the available computer-based programmes offer students malleable tools to be productive in multiple learning environments. Most importantly, technology-enhanced learning does not only prompt production, but it also fosters the authenticity of the learning experiences needed for schooling.

The use of technology for expression is the fourth and final criterion for applying technology in education (information (Bruce and Levin, 1997). Technology is reputed for its ability to enhance freedom of expression. It provides welcoming environments for respect and tolerance to characterise human interaction. For instance, the social media can be used to create learning environments with a lot of opportunities for students to express themselves and learn from one another. It should be noted that the influence schooling has on education goes against the inclusive character of education. The fact is that the offerings of technology compensate for the rigidity of institutionalised education. They simply give students control over their own learning.

Dewey (1938)'s conception of educational technology offers viable perspectives for technology implementation in education. Outside the educational sphere, technology might have a separate existence and a distinct identity. It serves different purposes under different circumstances. 
But, the incorporation of technology in education causes the two construct to belong dependently of one another. Technology becomes a condition for education. More than that, the use of technology in education is a logical outcome if we consider social progress and the individual's predispositions to impact their society.

\subsection{Dusek (2006)'s conceptualisation of} educational technology

Dewey (1938) 's views on education and technology pave the way for more explanations on the nature of educational technology. Dusek (2006, pp.26-38) redefines the criteria needed for evaluating technology. The author departs from the impertinence of prior definitions of technology to substantiate a comprehensive view of the capabilities and affordances of technology.

An example of defining technology in a too narrow manner is the common contemporary tendency to mean by "technology" solely computers and cell phones, leaving out all of machine technology, let alone other technology. A case of defining technology in a manner that may be too broad is B. F. Skinner's inclusion of all human activity in technology. (Dusek, 2006, p.31)

There is an explicit concern with two definitions of technology. One is criticised for being biased towards a limited range of technology, notably hardware technology while the other is rejected for being extrinsic to the true character of technology. Eventually, the author forwards three characterisations of technology: technology as hardware, technology as rules and technology as a system. Technology as hardware accounts for the tangible forms of technology used for practical reasons (ibid, p. 32). Technology as rules specifies the intangible manifestations of technology. It designates all the process and codes used in the production of software applications. Technology as a system goes beyond the hardware-software dichotomy. It combines tangible and intangible attributes of technology and synchronises the whole with the context of implementation. Also, the human factor is made a determining factor in the characterisation of technology.

Dusek's conception of technology as a system prevails over prior definitions of technology because it offers a more complete characterisation of the impact technology has on society. The system approach to technology is well suited to the educational context. It assumes that the influences from technology are polysemous and multidirectional. Technology is consequential in every structure and the educational discourse is no exception. Still, technology use for educational purposes must synchronise with the intent of the implementers. Technology cannot have a separate existence and operate in a system of its own. For example, a computer is a technology tool with distinct characteristics. Still, our understanding of a computer is never complete unless we connect it to human use and manipulation. The same logic applies to educational technology. The offerings from educational technology are only consequential when they combine with valid theoretical and pedagogical structures.

The system approach to technology remedies for the lack of coherence in prior definitions of technology. It accounts for the shortcomings of the hardware approach and the software approach. More than that, technology as a system increases the possibilities for implementation. Technology is an instrument for impacting one's environment. This instrument is responsive to the intent of the implementers and the context of implementation.

\section{CONSTRUCTIVISM}

Constructivism is a school of thought with distinct epistemologies about the nature of knowledge and learning (Doolittle \& Hicks, 2012, p 73-76). The roots of Constructivism are traced back to the philosophical stands by Thomas Hobbes (1588-1679, as cited in Dusek, 2006, p.99). The Hobbesian philosophy maintains that arbitrariness is a key feature in the construction of knowledge. The means for constructing knowledge about the world vary and so are the available constructs about the world. In the same line of thought, Immanuel Kant (17241804, as cited in Dusek, 2006, p.99) capitalises on the human mind's ability to generate structured understandings of the world. The Kantian commitment to rationalise the construction of knowledge does not negate the existence of realities that are inaccessible to Man's perceptions. Also, the philosophical positions held by Hobbes and Kant are well articulated in Jean Piaget's (1896-1980) conception of learning. Piaget (as cited in Dusek, 2006, p. 201) champions constructivism in education by means of his theory of "accommodation" and "assimilation" in learning. Accommodation designates the cognitive processes by which prior mental models are altered to accept new perceptions of the world. On the other hand, assimilation processes allow for the integration of new information into an existing mental database of pre-established experiences. Piaget's dichotomy is further explained by Fosnot (1996) whose definition of learning is as follows:

The theory describes knowledge as temporary developmental, non-objective, internally constructed, and socially and culturally mediated. Learning from this perspective is viewed as a self-regulatory process of 
struggling with the conflict between existing personal models of the world and discrepant new insights. (p. ix)

Indeed, constructivism combines a theory of knowledge and learning. Knowledge is viewed as an ongoing product of much subjectivity as it stands dependently of the individual's involvement. Also, learning is presented as a cognitive process where a subjective reality is one possible version out of many versions of the same reality. Constructivism represents the culmination of multiple lines of thought. They all converge to offer a viable theory of knowledge and learning that is applicable to different contexts. Constructivism is credited for its plausible contributions to the educational field as it forwards a clear theoretical framework for conceptualising learning.

\section{SOCIAL CONSTRUCTIVISM}

Social constructivism is an extension of constructivism with sociological perspectives on the nature of knowledge and acquisition (Fosnot, 1996). The influence of constructivism on its socially oriented form is incontestable. Still, the social constructivist approach emphasises the determining role of social interactivity in the construction of knowledge. Acquisition and learning are not the pure products of assimilation and accommodation. The social constructivist approach refutes the existence of an objective version of a unified reality. It emphasises the social nature of knowledge which cannot be attained solely by means of cognitive enquiry (Doolittle \& Hicks, 2003, p.78). Social constructivism enables new perspectives form where to conceptualise knowledge and learning. The social transactions of meaning and the processes needed for learning are knowledge on their own. For learning to take place, there should be a social context with opportunities for interaction between people.

\section{SOCIAL CONSTRUCTIVIST THEORY OF LEARNING}

The existing frameworks used for conceptualising learning carry varied assumptions about the nature of learning and its realisations. The choice of a theory of learning has direct implications for educational policy as a whole. It impacts the curriculum design, instructional material and teaching methodology. The social constructivist theory of learning is one of many doctrines which are in competition for the most plausible characterisation of learning. For the purpose of this study, the fundamentals of the social constructivist theory of learning are exposed and contrasted to competing paradigms.

The social constructivist theory of learning originates from a non-positivistic paradigm, which is contrasted to positivistic doctrines in the kind of behaviourism and instructivism (Fosnot \& Perry, 1996). Indeed, social constructivism capitalises on the impact of society on knowledge acquisition, and the same logic applies to learning. Social interactivity is a condition for learning. In the absence of an objective truth, learners need to trust their own understandings of the world for the construction of personalised versions of a constantly changing reality. The legitimacy of subjective knowledge is central to the social constructivist theory of learning. The process by means of which learners manage to obtain knowledge is consequential because it attaches meanings of its own to the final outcomes of learning.

The Social Constructivist views of learning call into question competing paradigms where learning is viewed from different perspectives. Eventually, the behaviourist model of learning emphasises the automaticity of learning which is structured by means of a stimulus-response sequence of actions (Fosnot \& Perry, 1996). The process of learning is predetermined and managed to resist the impact of external variables. With the accent being placed on learners' abilities to perform automatic and quantifiable behavioural attitudes, the learners' personal contributions to learning are overlooked and deemed obstructive in nature. The learning process in behaviourism is unidimensional. It targets proficiency by means of a series of controlled practices, with maximum attention given to external feedback and motivation.

Relatedly, instructionism lines up with the behaviourist theory of learning. Both philosophical orientations emphasise the role of instruction in shaping the final outcomes from learning (Anderson \& kanuka, 1999). The instructivist model of learning targets the completion perceptible competencies on the part of learners. The focus is on the skills and competencies needed for learners to be functional and responsive to the learning processes. Educators are required to optimise the learning environments in such ways that would offer suitable conditions for the execution of distinct learning instructions. The instructivist orientation in learning offers a sequential process that ensures the compatibility of the learning approaches with the target competencies. For educators, the process of learning needs to be controlled with no room for learners to interfere with its automaticity. Learners' levels of competency are regularly assessed against a performance list that is exploited for sequencing further learning activities for maximum proficiency.

\section{PEDAGOGICAL SOCIAL CONSTRUCTIVISM}

In the previous section, the epistemological assumptions about learning were exposed and researched 
for the effect they have on teaching and learning practices. For maximum efficiency, a theory of learning must convert into an equally valid pedagogy, susceptible to substantiate the legitimacy of the teaching methods used for instruction. The social constructivist tradition in education synchronises with the educational use of technology; also, it converts into a viable pedagogy (Brooks \& Brooks, 1993; Hendry, 1996; Jonassen, Peck, \& Wilson, 1999). These are the standards of validity for a social constructivist pedagogy (Adams, 2006).

Learning is valued for its own contributions to learners' self- development. As mentioned earlier in this section, the social constructivist theory of learning claims high levels of learner-centeredness and so is its respective pedagogy. It is entirely committed to assist learners in their own manipulation and construction of knowledge (Adams, 2006). In parallel, the teaching practices are required to optimise a socially appealing environment for learning. The social component in learning is made essential to knowledge acquisition and it should be prioritised by means of teaching practices that encourage learners to be active participants in making conscious decisions about their own learning (Packer \& Boicoechea, 2000, p.232). The teaching orientation that goes with such views of learning is one that empowers the process of learning from the inside allowing for the autonomy of learners. Also, by placing the accent on learning rather than its final outputs, the teaching practices gain much in terms of authenticity. Teachers afford to adapt to the needs of learners.

Learning is a multi-dimensional process through which social and cultural interactivity is developed into meaningful output (Doolittle \& Hicks, 2012, p.84). The social constructivist theory of knowledge acknowledges the role of cognition in the construction of knowledge. Still, learning cannot be solely attributed to the learner's mental abilities. Learning outputs are not cognitive structures, exclusive to the transmission and reproduction of knowledge. The outputs of learning belong dependently of the processes from where they originate. Context is a consequential factor in the process of learning and it needs to be socially and culturally rich to stimulate learners' participation. For teachers to optimise a supportive learning environment, they are entitled to engage learners in real-life situations.

The learner-teacher relationship is a determining factor in learning (Adams, 2006, p. 250). The social constructivist pedagogy values learners' contributions to their own learning. The nature of the relationship between learners and the teacher and among learners themselves is marked by high levels of interactivity. Students and teachers contribute meanings of their own to the final outcomes form learning. For social constructivists, teaching does not entail the control of a passive audience of learners who are repeatedly instructed on how to complete controlled tasks for the purpose of shaping distinct competencies. A teacher fulfils different roles only to assist learners throughout the process of learning. A teacher serves as a facilitator, a coach, a guide a negotiator or an advisor. These teacher-roles are well suited to the theoretical foundation of social constructivism. Although social constructivism appears to favour socially enhanced modes of learning with multiple opportunities for learners to interact and negotiate constructs of their environment, the presence of a teacher is needed for maximising the interactivity of learners.

Testing is a process for accompanying learners throughout the different stages in their learning. For social constructivists, testing practices are needed to determine learners' levels of proficiency' (Adams, 2006, p.252). Testing is a form of extrinsic reward. Good grades have positive effect on pupils' further school performances. They sustain high levels of motivation among the highachievers. The social constructivists refuse to remove testing from its due context, being an integral part of learning. The importance of testing goes beyond the need for ranking learners' performances. Testing informs on the learners' failure to take advantage of their social environments. Testing cannot be removed from the context of learning, and so are its outcomes. They do not give feedback about what has or has not been learned as much as they orient the courses of action needed for better quality of learning.

The social constructivist theory of learning converts into distinct learning and teaching practices that capitalise on the social and cultural contents in education. As noted earlier in this paper, technology is a social and cultural phenomenon and its incorporation in education must line up with the learners' needs for authenticity. Technology use in education must activate socially-oriented modes of enquiry and enable learners to take full advantage of their social environment by means of self-directed cognition and interactivity. Such views on learning espouse a highly flexible pedagogy, one that is susceptible to put up with variety and differences among learners. Indeed, the social constructivist approach to learning offers multiple opportunities for advantageous implementations of technology for educational purposes.

\section{TECHNOLOGY-BASED PEDAGOGY}

The social constructivist orientation in education offers multiple possibilities for grounded incorporation of educational technology. It should be emphasised that our 
understanding of technology is never complete. Technology is a fast-evolving construct. The theoretical accounts about the potential of educational technology must combine with empirically valid educational strategies (Duffy \& Cunningham, 1996). The social constructivist thinking outlines the itineraries of implementation needed for a valid incorporation of educational technology (Herrington \& Oliver 2000, pp. 1-2). These are educational strategies that are supportive of the processes by which learners take advantage of technology throughout the different stages in their learning.

The potential of educational technology resides in its ability to promote social interactivity by means of which learners construct meanings of their own (Woo \& Reeves, 2007, pp. 18-20). The application of technology in education is not an independent process of inquiry. It belongs on a continuum only to serve learners' cognition in the construction of knowledge. The available communication tools and information technologies are to be optimised and used for educational purposes because they enable a diverse range of interactions. For instance, thanks to the web-based channels of communication, learners can take part in numerous transactions of meaning. These are quantity-enhanced learning opportunities that account for the utility of using technology as a means of enquiry. This particular dimension of technology use in education better assists teachers in their attempts to simulate learning environments with maximum opportunities for interaction between learners. Still, these technology-based learning opportunities need to be contextualised to synchronise with the objectives for which learning is organised. The social constructivist theory is up to this concern because it enables the impact of technology on social activity and it surely offers the means for a valid incorporation of educational technology.

The implementation of technology in education is needed to restore authenticity to institutionalised learning ((Herrington \& Oliver 2000, p.89). As it has been noted earlier in this paper, the danger with institutionalised learning resides in the rigidness of the framework by which it operates. Overemphasis on school-related formalities may obstruct the perspectives needed for authenticity in education. In this context, technology is well positioned to serve learners' needs for personalised learning experience. Indeed, this particular attribute of technology is in harmony with the theoretical foundation of social constructivism. Learning is a product of society that is constructed by means of social interactivity between the individual and their environment. Technology maximises and adds more authenticity to learners' intercourse with their environment, inside and outside school. As to the impact of technology on teaching and learning materials, the existing technology devices have revolutionised learning by offering viable alternatives to traditional teaching (Doolittle \& Hicks, 2012). Educational technology is a powerful means of instruction with much of a potential that has been proved in many educational contexts. Indeed, technology offers the means for an authentic remake of institutionalised education. The traditional settings of schooling could be transformed into more personalised learning environments where educational outputs are constructed by means of real-life negotiation and interaction.

Social constructivist pedagogy is required to foster learner-centeredness (Herrington et al., 2004, as cited in Woo \& Reeves, 2007, p21). Taking into account the theoretical foundation of the social constructivist thinking, learning happens when there is a need and a context for interaction between individuals who are responsible for developing their own understandings of their environment. The learner is placed at the core of the learning process and so should be the teaching practices. Accordingly, learning must capitalise on learners' abilities to take control of their own environment. The implementation of technology in education needs to ease learners' productivity. Accessibility and self-development are the objectives for which technology is used in education. Indeed, technology-based education promotes active learning by providing learners with unlimited access to information. Learners are enabled to experiment on a wide range of educational inputs. Learning by doing is a key feature in this approach to learning because it guarantees the learner is at the centre of the learning process. Technology-enhanced learning provides many learning opportunities with maximum involvement of learners. For example, Internet-based activities offer a viable platform for collaborative learning. Learners are given the means to structure their own learning at their most convenient pace. The most notable gain from this pedagogy is the promotion of autonomous learning. Learning is upgraded from being a series of teacher-centred activities to an uncontrolled platform with ample opportunities for learners to determine their own style of learning.

Technology use in education should be oriented towards the development of lifelong competencies in learners (Doolittle \& Hicks, 2003, p. 92). Technologyenhanced education synchronises with the underlying theory of social constructivism. Knowledge constructs are the function of social interactivity. The social constructivist theory advocates the use of teaching and learning practices that boost learners' productivity outside 
school. The challenge for teachers goes beyond sustaining the legitimacy of school-based input. For learning to be advantageous to learners, it must be true to learners' perceptions of their environment. The accent is on learners' abilities to be functional outside school. The available technologies in the field of education boost learners' autonomy. More than that, they enable the skills needed for learners to unlock their own ascension. The main reasons for using technology at school reside in their ability to assist learners after school where the presence of technology is surely indisputable. Knowing how to use technology for self-development is no longer an option; it is a fundamental reality. The offerings of technology need to convert into a viable pedagogy with opportunities for learners to demonstrate creative and critical thinking.

Technology-enhanced learning is required to impact learners at various points in their learning (Woo \& Reeves, 2007 , p. 20). Learners must use technology to further their understanding of their learning environment in its entirety. Knowledge constructs relating to one or more disciplines must be connected and contextualised to serve a common goal. By allowing learners to make meaningful connections between distinct disciplines, learners are enabled to take full advantage of their social environments. The process of learning is empowered because it operates on a wide range of structures. Indeed, technology use in education is supportive of this pedagogy. For instance, web-based environments ease the circulation of information. Because of this technological support, learners throughout the process of learning are able to detach study concepts from their original contexts for further examination and analysis. With this kind of learning practices, learners are empowered to take good care of their own learning. Also, the educational outputs from learning transcend the conceptual barriers separating school disciplines. They become a condition for students to be functional in real life situations.

\section{CONCLUSIONS}

Indeed, the theoretical frameworks used for assessing the relationship between education and technology provide credible estimates of the potential of educational technology. Technology use in education is a logical consequence of the wide spread of technology. The two constructs cannot be detached from one another and any attempt to do so would only further the gap separating schooling from real life objectives. The challenge for educators is to cater for the synergy between education and technology and foster the impact of educational technology on learning.
The social constructivist orientation in education synchronises with the fundamentals of educational technology. The social constructivist thinking offers different perspectives for a valid implementation of technology for educational purposes. Also, the social constructivist pedagogy substantiates the intent of educational technology. The pedagogical strategies used for orienting technology use in education are studentcentred. They simultaneously emphasise the compatibility of education with technology and the ability of the two to cause life-long competencies in students.

\section{REFERENCES}

[1] Adams, P. (2006). Exploring social constructivism: Theories and practicalities. Education, 34(3), 243-257.

[2] Brooks, J. G., \& Brooks, M. G. (1993). In search of understanding: The case for constructivistclassrooms. Alexandria, VA: Association for Supervision and Curriculum Development.

[3] Bruce, B., \& Levin, J. (1997). Educational technology: Media for inquiry, communication, construction, and expression). Journal of Educational Computing Research 17(1), 79-102.

[4] Dewey, J. (1938). Logic, the theory of inquiry. New York: Holt Publishing.

[5] Doolittle, P. E., \& Hicks, D. (2003). Constructivism as a theoretical foundation for the use of technology in social studies. Theory \& Research in Social Education, 31(1), 72104.

[6] Duffy, T. M., \& Cunningham, D. J. (1996). Constructivism: Implications for the design and delivery of instruction. In D. H. Jonassen (Ed.), Handbook of research for educational communications and technology. New York: Macmillan.

[7] Dusek, V. (2006). Philosophy of technology: An introduction (Vol. 90). Malden Oxford Carlston: Blackwell.

[8] Hendry, G. D. (1996). Constructivism and educational practice. Australian Journal of Education, 40(1), 19-45.

[9] Herrington, J., \& Oliver, R. (2000). An instructional design framework for authentic learning environments. Educational Technology Research and Development, 48(3), $23-48$.

[10] Herrington, J., Reeves, T. C., Oliver, R., \& Woo, Y. (2004). Designing authentic activities in web-based courses. Journal of Computing in Higher Education, 16(1), 3-29. Retrieved on April 19 $19^{\text {th }}$ 2019, from http://www.flshbm.ma/images/actualites/2016 /Vision_VF_Fr.pdf

[11] Jonassen, D. H, Peck, K. L., \& Wilson, B. G. (1999). Learning with technology: A constructivist perspective. Upper Saddle River, NJ: Merrill.

[12] Lakhana, A. (2014). What is Educational Technology? An Inquiry into the Meaning, Use, and Reciprocity of Technology. Canadian Journal of Learning \& Technology, 40(3). 
[13] Packer, M. J., \& Goicoechea, J. (2000). Sociocultural and constructivist theories of learning: Ontology, not just epistemology. Educational psychologist, 35(4), 227-241.

[14] Woo, Y., \& Reeves, T. C. (2007). Meaningful interaction in web-based learning: A social constructivist interpretation. The Internet and higher education, 10(1), 1525. 